E. Furstenberg

J.S. Keller

J. Bujko

S. Halilu Bawa

\section{Maintenance energy requirement as a direct linear function of body weight}

\section{Erhaltungsenergiebedarf und Körpergewicht}

\section{Aim}

The purpose of this study was to examine the relationship between body weight as well as its components on the rate of carbon dioxide production in rats.

\section{Materials and methods}

The experiment was carried out in 44 female Wistar rats. Animals arrived at the research unit with a body weight of 30-92 g. They were fed ad libitum a commercial stock diet and adapted to their new environment for the period when required initial body weight was achieved i.e. 60 150 g. After this period, rats were given a constant amount of feed, calculated on the basis of the correlation between body weight and feed consumption until maximum body weight was reached. At the end of the experiment chemical composition of carcass was determined.

Carbon dioxide production was measured in an opened-circuit respiratory chamber with the use of an infrared carbon dioxide analyzer - UNOR 6N (Maihak, Germany).

\section{Conclusions}

Results achieved in this study revealed that

1. Maintenance energy requirement was a direct linear function of the body weight of growing female rats.

2. Body fatness exerted no influence on basal metabolic rate in experimental rats.

3. The correlation found between lean body mass, protein body mass or dry body mass and basal metabolic rate was by no means better than the one between body mass and basal metabolic rate.

E. Furstenber · J.S. Keller - J. Bujko

S. Halilu Bawa

Faculty of Human Nutrition and Home

Economics. Department of Dietetics

and Nutritional Physiology

Warsaw Agricultural University

ul. Nowoursynowska 166

PL-02787 Warsaw

Poland 